THURSDAY, APRIL I7, I913.

A TEXT-BOOK OF HUMAN PHYSIOLOGY.

Physiologie des Menschen. By Prof. Luigi Luciani. Ins Deutsche übertragen und bearbeitet von Prof. S. Baglioni und Dr. H. Winterstein, mit einer Einführung von Prof. M. Verworn. Lieferung elfte-fünfzehnte. Pp. I $-782+$ viii. (Jena: Gustav Fischer, rgo8-I9I I.) Price 4 marks each.

THE present five parts complete the German version of Luciani's "Text-book of Human Physiology." The first part opens with the general physiology of sensation, giving a brief but adequate critical review of Johannes Müller's doctrine of specific nerve energies, and of Weber and Fechner's psycho-physical law governing the quantitative relationship between stimulus and sensation. The greater part of the fifty-one pages composing the first chapter is devoted to cutaneous sensations. The second chapter, occupying more than sixty pages, deals with internal and visceral sensations. While the exposition is full of detail and interest, it would have gained in clearness by a more thorough account of the classification of cutaneous and deep sensations suggested by Head and Rivers. The second chapter closes with an excellent account of the labyrinthine sensations.

The sense of taste forms the subject-matter of the third chapter, and occupies more than thirty pages. The survey given is exceptionally interesting and complete, and is well illustrated by plates. The fourth chapter is devoted to the sense of smell, and is prefaced by a brief description of the structural features of the organ of smell. The very large number of qualitative variations in odours renders the classification of olfactory sensations an almost impossible task. The author gives a very interesting and critical account of the classifications attempted by Linné and $Z$ waardemaker.

Nearly eighty pages are given up to the sense of hearing, which occupies the fifth chapter. It is impossible in a brief review to do justice to the excellence of the account given. The two following errors may be noted with a view to their correction in future editions. On p. 208 the word "perilymph" is used instead of "endolymph." Some confusion has also arisen in the discussion of the theory of hearing suggested by Helmholtz. In consequence, the first two sentences of the final paragraph of p. 229 require to be re-written. Fortunately, since the two sentences are obviously contradictory, there is little risk of the reader being led astray.

The sixth chapter deals fully with the dioptric mechanisms of the eye; while chapter vii. is devoted to the study of the structural features and N). 2268, VOL. 9I] properties of the retina, and the retinal changes. concerned with vision. The description of tip electromotive changes occurring in the retina as the result of exposure to light does not include the more recent results obtained by the use of the string galvanometer.

Chapter viii. contains an extremely lucid account of the movements of the eyeballs, of binocular vision, and of visual perceptions and judgments. It closes with the description of the protective and secretory mechanisms of the eyeball.

General metabolism forms the subject-matter of chapter ix. The historical development of the subject is fully discussed. A necessarily brief but clear account is given of the methods employed for the estimation of the intake of foodstuffs and oxygen, and the output of solid and gaseous waste products. Chapter $x$. is devoted to the discussion of the regulation and measurement of heat production in the organism; while chapter xi. deals with the various theories of nutrition, and the experimental and statistical evidence upon which they are based. Chapters xii. and xiii. are given up to the physiology of reproduction. An excellent survey of the physiology of pregnancy, parturition, and lactation is given in chapter xiv.

The subjects of development, growth, maturity, and senile decay occupy the fifteenti chapter. The two latter subjects receive a much more detailed treatment than is usual in textbooks of physiology, and the whole chapter is one of exceptional interest.

The wide view of the scope of physiology held by the author is well illustrated by the final chapter, which is anthropological in nature, dealing with the characteristics of the various races of mankind from the physiological point of view. It has been contributed by Prof. S. Baglioni.

Clearly no pains have been spared to make this text-book adequate for the needs of senior students of physiology, and Prof. Luciani may well be congratulated on the completion of a textbook which may fairly be described as a colossal task for one writer. The work is well and profusely illustrated and clearly printed.

\section{TYPICAL AMMONITES.}

Yorkshire Type Ammonites. Parts i-viii. Edited by S. S. Buckman. The original descriptions reprinted, and illustrated by figures of the types, reproduced from photographs mainly by J. W. Tutcher. (London: William Wesley and Son, I909-19I2.) Price $3^{s .6 d}$. net per part, post free.

W ${ }^{\mathrm{ITH}}$ the issue of the eighth part of Mr. S. S. Buckman's "Yorkshire Type Ammonites" the first volume of this important work is 